\title{
RELIABLITY OF CURVED TIMBER BEAM EXPOSED TO FIRE
}

\author{
Robert Pečenko, Tomaž Hozjan, Goran Turk \\ University of Ljubljana, Faculty of Civil and Geodetic Engineering, Ljubljana, Slovenia
}

\begin{abstract}
In this paper the performance based approach to determine the reliability of curved timber beam during the fire is presented. The reliability is preformed with Monte Carlo simulation method, where, in order to reduce the number of simulations, Latin hypercube sampling is applied. The uncertainties are implemented in the advanced calculation method, as randomly generated parameters for both thermal and mechanical analysis. At the end of the paper, the distribution of the mid-span displacement at $30 \mathrm{~min}, 45 \mathrm{~min}$ and at failure time is presented. In addition, failure time that satisfies safety requirement from the Eurocode $(\beta>3.8)$ is determined as well.
\end{abstract}

Keywords: reliability analysis, curved timber beam, fire, failure probability

\section{INTRODUCTION}

Timber elements are the principal structural members in many buildings. An important part of timber structures is represented by timber elements such as curved beam made from glue-laminated timber. Compared to the other structural materials, timber elements are recognized by their relatively good fire resistance, however, this does not automatically imply their safety from failures. At high temperatures and at the absence of oxygen, wood is subjected to solid thermal degradation, also known as pyrolysis, resulting in the extensive number of chemical compounds (DiBlasi, 2006). From the fire safety point of view, the most important reaction product is char. The formation of char layer has both positive and negative effects. Char layer has a low thermal conductivity and is from this aspect good thermal insulation for the remaining uncharred timber. On the other hand, the mechanical properties of char layer are practically negligible, therefore char layer is not contributing to the bearing capacity of timber element. In addition, it is often very difficult to extinguish fire in the objects made of timber. For this reason, most of the timber cross-section during fire is carbonized, which, in combination with mechanical load, usually leads to failure.

The today's practice of fire-resistance analysis remains deterministic. However, the destructive fire potential is influenced by many random factors and is thus highly uncertain. In the presented paper, uncertainties are inherent in the advanced calculation method which allows us to analyse the behaviour of the structure and its part during the fire. The analysis is divided in tree separated phases. In the first phase the development of temperatures with time in the fire room according to the standard fire curve is considered (ISO 834, 1999). In the second phase the temperature state of timber beam is analysed, taking into account uncertain convective heat transfer coefficient, emissivity of timber as well as thermal parameters of timber. Based on the temperature state of timber beam the mechanical analysis is performed in the third phase with the randomly generated strength and stiffness parameters and load data. At the end, the probability of failure at 45 minutes of fire exposure is investigated. Graphical presentation and statistical distribution of mid-span displacement for the timber beam at different times is presented as well. Finally, failure time that meets minimum reliability index $(\beta=3.8)$ is calculated.

\section{THERMAL AND MECHANICAL MODEL}

Mathematical model for heat transfer in timber is described with Fourier partial differential equation $(E q$. (1)), together with corresponding boundary conditions at the contact between the timber section and the surrounding area $(E q .(2))$. 


$$
\begin{gathered}
\nabla(k \nabla T)-\rho c \frac{\partial T}{\partial t}=0, \\
q_{c r}=k \frac{\partial T}{\partial n} .
\end{gathered}
$$

Here $k$ is the conductivity of timber, $\rho$ is the density, $c$ specific heat and $\partial T / \partial n$ is the derivative of temperature normal to the surface. Further, $q_{c r}$ is heat flux composed of convective and radiative part:

$$
q_{c r}=\alpha_{c}\left(T_{\infty}-T_{m}\right)+\sigma \varepsilon_{m}\left(T_{\infty}^{4}-T_{m}^{4}\right),
$$

where $\alpha_{c}$ represents heat transfer coefficient, $\varepsilon_{m}$ is the timber surface emissivity, $\sigma$ is StefanBoltzmann constant, $T_{\infty}$ is fire temperature and $T_{m}$ is timber surface temperature.

The finite element formulation for the mechanical analysis is based on Reissner's kinematically exact model of the beam where large membrane and flexural deformations are allowed (Reissner, 1972) and the effect of the shear strain on the deformation of the beam is taken into account as well. The geometric extensional strain is a function of extensional strain of the centroidal axis $\varepsilon$ and its pseudocurvature $\kappa$. The Bernoulli hypothesis is considered. An important assumption in this model is the additive decomposition of the increment of geometric extensional strain $D$ on the increment of mechanical extensional strain $D_{m}$ and thermal strain increment $D_{T}$.

$$
\Delta D=\Delta D_{m}+\Delta D_{T}
$$

In the presented model failure occurs when the tangent stiffness matrix of structure becomes singular which can take place due to the global instability of the structure or due to the material failure. Detailed description about the mechanical model is found in Bratina et al. (2003).

\section{STATISTICAL DISTRIBUTION OF THE VARIABLES}

\subsection{Variables for the thermal analysis}

Parameters in the thermal analysis that were considered as random variables are: density of wood $\rho$, thermal conductivity $k$, initial moisture content $m_{0}$, convective coefficient $\alpha_{c}$, and surface emissivity $\varepsilon_{m}$.

The density of wood at room temperature is normally distributed $\left(\rho_{0, \text { norm }}\right)$, with the mean of 400 $\mathrm{kg} / \mathrm{m}^{3}$ and coefficient of variation 0.1 (JCCS, 2001). When a variable is described with normal distribution, it may in some cases take a value that is not possible, for instance, a negative value for density. Thus, initial density is limited with $\rho_{0, \min }=250$ and $\rho_{0, \max }=600$. Temperature dependency of density is taken into account according to EN 1995-1-2 (2005). Density of the timber at given temperature is therefore determined as a product of initial density of timber and density reduction factor $\left(k_{\rho, T}\right)$.

$$
\rho=\rho_{0, \text { norm }} k_{\rho, T}
$$

The same distribution type and coefficient of the variance is assumed (normal, COV $=0.1$ ) for thermal conductivity. The mean value for the conductivity at the room temperature is $0.12 \mathrm{~W} / \mathrm{mK}$ and is limited with $k_{0, \min }=0.09 \mathrm{~W} / \mathrm{mK}$ and $k_{0, \max }=0.20 \mathrm{~W} / \mathrm{mK}$. Moreover, thermal conductivity of timber is a function of temperature, its relationship is found in EN 1995-1-2 (2005). It and can be described with the family of curves presented in Fig. 1. In general, the number of curves is the same as the number of simulations. Due to the simplicity only seven different curves are presented. 


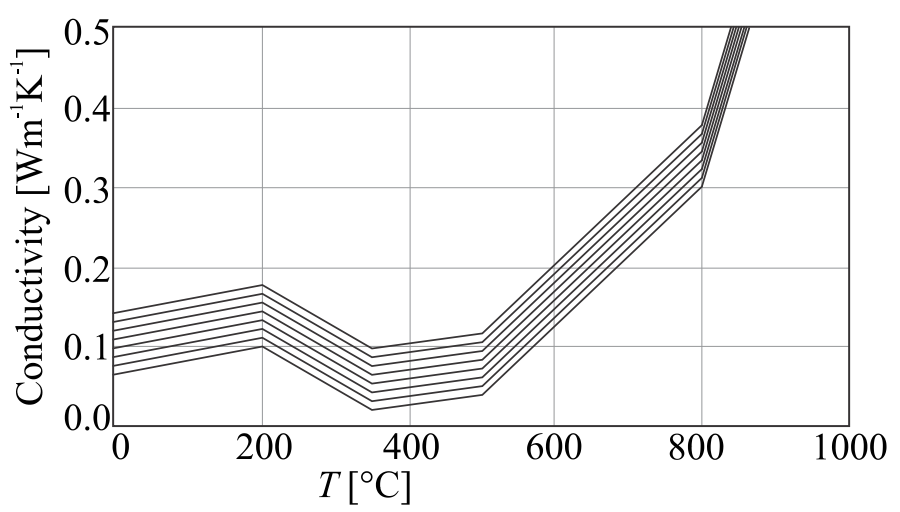

Fig. 1 Family of curves describing the conductivity of timber

Table 1 presents the statistical distributions and other data for the remaining three thermal variables. To the authors knowledge there is no data found in the literature to describe their statistical distribution and correlations. However, it is know that these variables are not constant and are dependent on many variables/parameters. For example, a painted timber beam may result in different surface emissivity, increased air flow during fire leads to increased heat transfer coefficient, etc. Furthermore, moisture content in timber is dependent on the relative humidity of the environment and is described with sorption the isotherm given by Anderson and McCharty (1963). Minimal value for the moisture content $\left(m_{0, \max }=0\right)$ corresponds to the totally dry environment $(\mathrm{RH}=0 \%)$ and maximal value $\left(m_{0, \max }=0.3\right)$ to the totally saturated one $(\mathrm{RH}=100 \%)$. Mean value $\left(m_{0, \text { mean }}=0.12\right)$ is found at $60 \%$ of relative humidity, which is the usual relative humidity in buildings. The impact of moisture can be indirectly considered through the increased density for the temperatures below $100^{\circ} \mathrm{C}$, as proposed in EN 1995-1-2 (2005):

$$
\rho\left(T \leq 100^{\circ} \mathrm{C}\right)=\left(1+m_{0, \text { norm }}\right) \rho_{0, \text { norm }}
$$

Table 1 Statistical distributions and coefficient of variations for the thermal analysis

\begin{tabular}{lccccc}
\hline \multicolumn{1}{c}{ Parameter } & Distribution & COV & Mean & Min & Max \\
Convective coefficient $-\alpha_{c}$ & Normal & 15 & $25^{*}$ & $35^{*}$ & $15^{*}$ \\
Surface emissivity $-\varepsilon_{m}$ & Normal & 15 & 0.7 & 0.5 & 1 \\
Moisture content $-m_{0}$ & Normal & 40 & 0.12 & 0 & 0.3 \\
*units: $\mathrm{W} / \mathrm{m}^{2} \mathrm{~K}$ & & & & &
\end{tabular}

\subsection{Variables for the mechanical analysis}

The largest test sample available in order to determine the glulam bending strength distribution was obtained in a joint Nordic project on the reliability of timber (Ranta-Maunus, 2001). A log-normal distribution with the coefficient of variation of $15 \%$ was recommended. Similarly, log-normal distribution with the coefficient of variation of $13 \%$ for bending modulus of elasticity was proposed (JCCS, 2001). The characteristic strength and mean value for modulus at room temperature, taken for our case study are: $f_{\text {mean }}=3 \mathrm{kN} / \mathrm{cm}^{2}$ and $E_{0 \text {,mean }}=1200 \mathrm{kN} / \mathrm{cm}^{2}$. Temperature dependency of both, modulus of elasticity and strength, are considered according to EN 1995-1-2 (2005).

$$
\begin{gathered}
E=E_{0, \text { lognorm }} k_{\mathrm{E}, \mathrm{T}} \\
f=f_{0, \text { lognorm }} k_{\mathrm{f}, \mathrm{T}}
\end{gathered}
$$

where $k_{\mathrm{E}, \mathrm{T}}$ and $k_{\mathrm{f}, \mathrm{T}}$ are the reduction factors at given temperature. Statistical distributions and coefficient of variations for the mechanical analysis together with minimal and maximum values are presented in Table 2. 
Table 2 Statistical distributions and coefficient of variations for the mechanical analysis

\begin{tabular}{lccccc}
\hline \multicolumn{1}{c}{ Parameter } & Distribution & COV & Mean & Min & Max \\
Modulus of elasticity - $E$ & Normal & 13 & 1200 & 700 & 1600 \\
Strength $-f$ & Normal & 15 & 3 & 1 & 5 \\
Load $-q$ & Normal & 20 & $10^{*}$ & 5 & 20 \\
\hline *
\end{tabular}

The model for stress-strain relationship is found in Pečenko et al. (2013) where bi-linear relationship in compression and linear in tension zone is proposed. Despite the brittle behaviour of wood in tension, here also plasticity is allowed. This was proved to be more appropriate on the basis of verification of the mechanical model with the experiment carried out by Zhang et al. (2012). The considered limit plastic strain in compression is 0.06 and in tension 0.03 .

In the mechanical analysis the beam is loaded with uniform line load as presented in Fig. 2.

\section{RELIABILITY}

Reliability is the probability that a system will perform its function over a specified period of time and under specified service conditions. In term of the structural reliability, this yields in evaluation of structural failure by determining if the limit-state functions are exceeded (Choi et al., 2007). A powerful tool for reliability analysis, especially for the complex problems such as curved timber beam in fire, is Monte Carlo simulation method (MSC). The MSC can be applied to many practical problems and allows any type of the probability distribution for a random variable, it is easy to implement and finally it enables to compute the probability of failure with the desired precision. However, the disadvantage of the method is seen in the case of very low failure probability, where a large amount of simulations is needed, which can become time consuming. For this reason, variance reductions methods can be implemented in order to decrease the number of simulation. For the purposes of our study, Latin hypercube sampling was applied. Total number of simulation was 10134. Furthermore, since the variables are correlated (Table 3), the sampling matrix was modified according to the method proposed by Vořechovský and Novák (2009).

Table 3 Correlation coefficient matrix

\begin{tabular}{cccccccc}
\hline & $k$ & $m_{0}$ & $\alpha_{c}$ & $\varepsilon_{m}$ & $f$ & $E$ & load $-q$ \\
$\rho$ & 0.92 & 0 & 0 & 0 & 0.6 & 0.6 & 0 \\
$k$ & & 0 & 0 & 0 & 0.6 & 0.6 & 0 \\
$m_{0}$ & & & 0 & 0 & 0 & 0 & 0 \\
$\alpha_{c}$ & & & & 0.2 & 0 & 0 & 0 \\
$\varepsilon_{m}$ & & & & & 0 & 0 & 0 \\
$f$ & & & & & & 0.8 & 0 \\
$E$ & & & & & & & 0 \\
\hline
\end{tabular}

\subsection{Case}

All the necessary geometric, load and cross-sectional data are presented in Fig. 2. The length of the beam is $11.5 \mathrm{~m}$. 

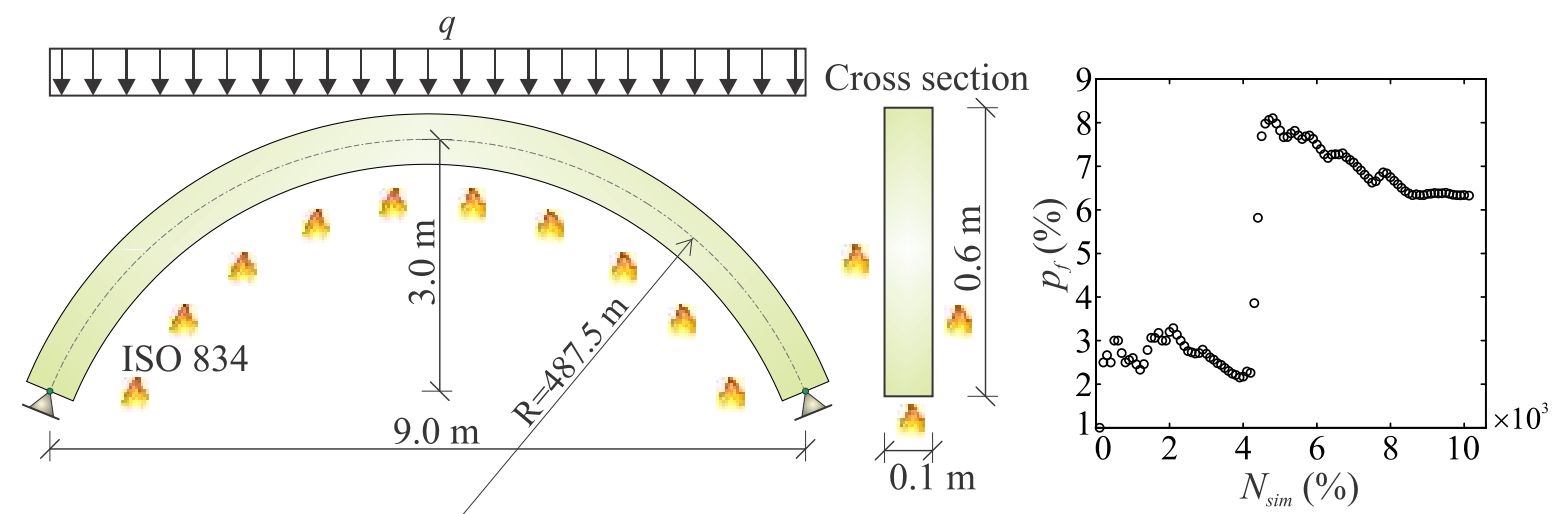

Fig. 2 Curved glulam beam: geometry, load, cross-section and probability of failure at $45 \mathrm{~min}$

On the right hand side of the Fig. 2 also the probability of failure at $45 \mathrm{~min}$ of fire exposure is depicted. After 8000 simulations, the probability of failure starts converging toward $6.33 \%$. This confirms that the final number of simulations $\left(N_{\text {sim,tot }}=10134\right)$ is sufficient to accurately predict the failure probability.
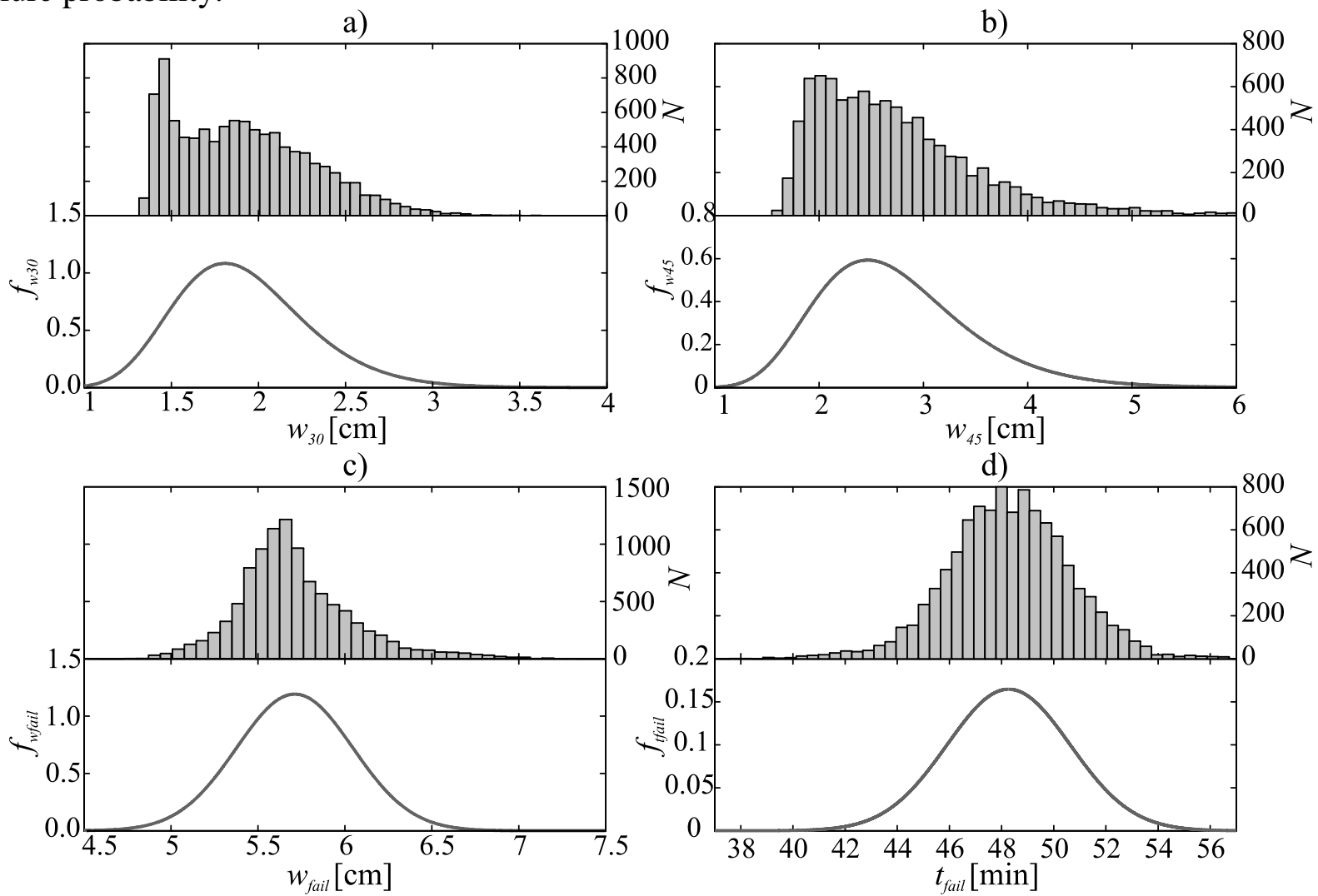

Fig. 3 Histograms and the probability density functions for: a) mid-span displacement at $30 \mathrm{~min}, w_{30} \mathrm{~b}$ ) midspan displacement at $45 \mathrm{~min}, w_{45} \mathrm{c}$ ) mid-span displacement at failure time, $w_{\text {fail }}$ and d) failure time $t_{\text {fail }}$

In the Fig. 3 the graphical representation of the distribution of numerical data and corresponding probability density functions for different output variables are shown. It was found that the midspan displacement at 30 and $45 \mathrm{~min}$ can be described with lognormal distribution. On the contrary, normal distribution is more suitable to characterize the failure time and mid-span displacement at failure time. The parameters to fit the distributions are shown in Table 4.

The target probability of failure during the structure lifetime for normal use defined in Eurocode (EN 1990, 2004) is $p_{t}=7.2310^{-5}$, which correspond to the reliability index $\beta=3.8$. The same 
safety requirement $(\beta>3.8)$ was also adopted as acceptable criteria for the fire safety of the analyzed structure. Failure time that meets this criterion is 39 minutes.

Table 4 Statistical distributions and coefficient of variations for different output variables

\begin{tabular}{cccc}
\hline Output variable & Distribution & COV & Mean \\
$w_{30}$ & Lognormal & 15 & $1.92[\mathrm{~cm}]$ \\
$w_{45}$ & Lognormal & 54 & $2.74[\mathrm{~cm}]$ \\
$w_{\text {fail }}$ & Normal & 5 & $5.71[\mathrm{~cm}]$ \\
$t_{\text {fail }}$ & Normal & 6 & $48.5[\mathrm{~min}]$ \\
\hline
\end{tabular}

\section{CONCLUSIONS}

The paper demonstrates performance based design for the reliability analysis of the curved timber beam exposed to fire. The reliability analysis was based on the Monte Carlo simulation approach where Latin Hypercube sampling was applied. The uncertainties were implemented in both thermal and mechanical analysis.

First, convergence of failure probability at 45 minutes depending on the number of simulation was shown $(6.33 \%)$, where it was shown that 10134 simulations was sufficient. Second, histograms and statistical distribution of different output variables were presented. It was found out, that the midspan displacement at 30 and 45 min can be described with lognormal distribution. On the other hand, the scatter of the failure time and the mid-span displacement at failure time were fitted better with normal distribution. At the end, failure time $t=39 \mathrm{~min}$ that satisfied the Eurocode safety requirement $(\beta>3.8)$ was determined.

\section{ACKNOWLEDGMENTS}

The work of Robert Pečenko was supported by the Slovenian Research Agency through the grant 1000-11310126. The support is gratefully acknowledged.

\section{REFERENCES}

Anderson N., McCharty J. 1962. Two parameter isotherm equation for fiber-water systems. Ind. Eng. Chem. Process Des. Dev., 2, p. 103-105.

Bratina S., Planinc I., Saje M., Turk G. 2003. Non-linear fire-resistance of reinforced concrete beams. Ind. Structural engineering and mechanics, 16(6), p. 695-712.

Choi S.K., Grandhi R.V., Canfield R.A. 2007. Reliability-based Structural Design, London, UK: SpringerVerlag.

DiBlasi C. 2006. Modeling chemical and physical processes of wood and biomass pyrolysis. Progr. Energ. Combust. Sci., 34(1), p. 47-90.

EN 1990: 2004 - Eurocode - Basis of structural design.

EN 1995-1-2: 2005 - Eurocode 5: Design of timber structures - Part 1-2: General - Structural fire design.

ISO 834. 1999. Fire-resistance Tests - Elements of Building Construction - Part 1: General Requirements. ISO 834-1. International Organization for Standardization, Geneva, Switzerland.

Joint Committee of Structural Safety (JCSS), 2001. Probabilistic model code. Available from: http://www.jcss.byg.dtu.dk/

Pečenko R., Hozjan T., Turk G. 2013. Numerical analysis of timber beam exposed to fire, in the Applications of Structural Fire Engineering, April 2013, Czech Republic, Prague, p.417-422.

Reissner E., 1972. On one-dimensional finite-strain beam theory: the plane problem. J. Appl. Math. Phys. (ZAMP), 23, p. 795-804.

Vořechovský M., Novák D. 2009. Correlation control in small-sample Monte Carlo type simulations I: A simulated annealing approach. Probabilist. Eng. Mech., 24, p. 452-462.

Zhang J., Xu Q.F., Xu Y.X., Wang B, Shang J.X. 2012. A numerical study on fire endurance of wood beams exposed to three-side fire. Journal of Zhejiang University - Science A: Applied Physics \& Engineering, 13(7), p. 491-505. 